\title{
Addiction psychiatry training experience, belief about addiction and brief screening for substance use among medical interns: A cross-sectional survey
}

\author{
Pokhrel P1, Rai N', Thapaliya $\mathrm{S}^{2}$, Shah B, ${ }^{3}$ Singh $\mathrm{SB}^{4}$, Sah MK ${ }^{4}$, Khadka ${ }^{1}$ Sharma PP \\ 1. Lecturer, Department of Psychiatry, KIST Medical College, Kathmandu, Nepal 2. Lecturer, \\ Department of Psychiatry, NMCTH, Birgunj, Nepal 3. Lecturer, Department of Psychiatry, PAHS, \\ Lalitpur, Nepal 4. Intern, KIST Medical College, Kathmandu, Nepal 5. Professor, Department of \\ Psychiatry, KIST Medical College, Kathmandu, Nepal
}

E-mail *Corresponding author: prabkums@gmail.com

\begin{abstract}
Introduction: Substance use and Substance Use Disorders (SUDs) have been shown to contribute substantially to the global burden of disease. However health workers belief system and attitude towards understanding and conceptualizing addiction makes the difference in the approach and treatment of the condition. This study tries to focus on the understanding and belief system of medical interns, and to see and contrast if their use of substance and their training about addiction during MBBS makes any difference in understanding and approaching addiction related cases.
\end{abstract}

Material And Method: This is a cross- sectional, onetime assessment of medical interns working in KIST medical college and teaching hospital based on questionnaires and likert scale assessing addiction belief strength from time frame of April 2019 to 15th of May 2019. The sampling method will be convenient sampling method and finding will be evaluated further.

Results: Out of 61 participants, $69 \%$ had completed psychiatry posting and were satisfied with their approach to patients with addiction related issues. Majority of them believed in disease model and their use of substance didn't negatively influence the approach to patient care.

Conclusion: Good exposure, training and skills given to students during MBBS years on addiction related diagnosis and treatment does help to understand addiction issues better and treat it as a biological model.

Keywords: Substance Use, Interns, Training, Beliefs

\section{INTRODUCTION}

Substance use and Substance Use Disorders (SUDs) have been shown to contribute substantially to the global burden of disease, both directly and indirectly. ${ }^{1}$ Inspite of the high prevalence and the associated morbidity and mortality of these disorders, only a fraction of individuals suffering from these disorders receives treatment. It is estimated that $<10 \%$ of the individuals who need treatment for SUDs actually receive treatment. ${ }^{2}$ This treatment gap in substance abuse services may be related to inadequate screening efforts by health care professionals and reflect biases and negative attitudes toward patients with SUDs. There have been few studies, which have suggested that even physicians believe that alcohol addictions are self-induced disease beyond medical model ${ }^{3,4}$. In the context of Nepal, many people with addiction are treated in rehabilitation centers without the supervision of doctors ${ }^{5,6}$. Many are referred by doctors who are either unaware or do not believe in medical model of treatment. Poor knowledge and personal belief system in relation to addiction 
may also be secondary to poor curriculum, teaching and exposure to clinical practice. ${ }^{7}$

Internship is the first exposure to supervised clinical practice and could be the last formal chance to study and care about addiction related issues provided they do not; specialize in psychiatry and drug related subjects. In Nepal, there are paucity of literature researching these aspects. So it becomes important to find out belief system of young budding doctors. Highlighting the research gap, this study is being conducted with the aim of exploring belief among medical interns doctors towards alcohol and drug use disorders, associated factors and whether the belief varies depending upon exposure to SUD cases during their clinical Psychiatry teaching and clinical posting.

\section{MATERIAL AND METHOD}

It was a cross sectional, single time assessment based quantitative study. Groups of medical interns working in KISTMCTH were approached for the study. The overlapping period where one group of interns were about to finish their internship and next group have just begun was chosen so that we can also take data of those students who have not finished psychiatry posting to see if belief system remains different. All the interns were working in the study frame were approached. Written consent was taken. Convenient sampling method was used and results were analyzed. Only those data, which was complete, was taken into study. The study period was from April 2019 and data entry was completed on 15th of May 2019. Ethical clearance was taken from IRC KISTMCTH. Total 66 responded to the call out of potential students. Few interns couldn't be reached. Few of them were on leave and few had postings outside hospitals. Out of 66,5 hadn't completed the form and so only 61 were taken for study .All the questions are in English language which is understandable to the participants. They were evaluated under following headings. Socio demographic profile sheet, Clinical Psychiatry Training details were used. Following scales were used.

The Addiction Belief Scale (ABS): The Addiction Belief Scale (ABS) evaluates the addiction versus the free-will model concept and the confidence with it. This instrument was developed to equal the goals, style of treatment and temporal demands of treatment of the clients and the providers. The participants are asked to respond an 18 item assessment using a 5 - point Likert style response. ${ }^{8} \mathrm{Few}$ of the sample questions were like e.g (question no 5)Addiction is an all-or nothing disease. A person cannot become a temporary drug addict and a mild drinking or drug problem. Question no (16) -Drug addicts and alcoholics can find their own ways out of addiction, without outside help, given the opportunity.

Brief tobacco, alcohol and drug use screening questionnaire: Questionnaire has been developed for the study to briefly screen the participants for tobacco, alcohol, cannabis and drug use. It consists of 11 items which cover the life time and current history of tobacco, alcohol, cannabis and other drugs among the participants, their family members/friends and the cultural acceptability of substance use. Each question can be responded by either 'Yes' or 'No'. The findings will be useful to explore how use of these substances by the participants affects their belief and attitude towards substance use treatment.

The Statistical package for social sciences (SPSS) Windows version 21 was used to analyze the data (SPSS Inc., Chicago, IL, USA). For summarizing the data (both socio-demographic and clinical), mean and standard deviations were performed for continuous data. Discrete data were expressed in number and percentage. Independent sample t-test was used to compare the continuous variables.

\section{RESULT}

The average age of medical interns was 24.59 with $52.5 \%$ being female interns. All of them were unmarried. Two groups of interns were noted, one who had or on the verge of finishing the internship and other group had just started the internship (2months of posting). Almost all were Hindus. Out of all the interns, $60.7 \%$ had finished two weeks period of clinical rotation in psychiatry where they had to have night duties, take detail history and evaluation of admitted cases. Interns during their study period had an average of 3 hours lecture classes and 3 hours of clinical posting where $98.4 \%$ had opportunity to have direct interaction with the patient related to substance abuse mostly in the form of clinical 
interview (29.5\%) and clinical rounds (32.8\%). Around $85.2 \%$ of interns were happy with this interaction. Most of the participants wanted to practice medicine and $16.4 \%$ also wanted to specialize in psychiatry in the future. (Details in table no 1 and 2 )

Table 1: Socio-Demographic Variables

\begin{tabular}{|l|l|}
\hline Details & Result \\
\hline Age in years & \\
Mean $\pm S D$ & $24.59 \pm 1.08$ years \\
Minimum & 22 years \\
Maximum & 28 years \\
\hline Gender & \\
Male & $47.5 \%$ \\
Female & $52.5 \%$ \\
\hline
\end{tabular}

Table 2. Showing Training Details

\begin{tabular}{|c|c|}
\hline $\begin{array}{l}\text { Total duration of internship } \\
\text { Mean } \pm S D \\
\text { Minimum } \\
\text { Maximum }\end{array}$ & $\begin{array}{l}7.16 \pm 4.86 \text { month } \\
2 \text { months } \\
12 \text { months }\end{array}$ \\
\hline $\begin{array}{l}\text { Posting of psychiatry completed } \\
\text { Yes } \\
\text { No }\end{array}$ & $\begin{array}{l}\text { Yes }=37(60.7 \%) \\
\mathrm{No}=24(39.3 \%)\end{array}$ \\
\hline $\begin{array}{l}\text { Hours of clinical lecture in addiction } \\
\text { psychiatry } \\
\text { Mean } \pm S D \\
\text { Minimum } \\
\text { Maximum }\end{array}$ & $\begin{array}{l}2.70 \pm 1.26 \text { hour } \\
1 \text { hours } \\
6 \text { hours }\end{array}$ \\
\hline $\begin{array}{l}\text { Hours of clinical posting in addiction } \\
\text { psychiatry } \\
\text { Mean } \pm S D \\
\text { Minimum } \\
\text { Maximum }\end{array}$ & $\begin{array}{l}2.98 \pm 1.98 \text { hours } \\
1 \text { hours } \\
9 \text { hours }\end{array}$ \\
\hline $\begin{array}{l}\text { Clinical experience types in addiction } \\
\text { psychiatry } \\
\text { Clinical interview } \\
\text { Clinical Rounds } \\
\text { Counseling/ Psycho-education } \\
\text { Clinical Interview, Rounds and } \\
\text { counseling } \\
\text { Clinical interview and Clinical Rounds }\end{array}$ & $\begin{array}{l}18(29.5 \%) \\
20(32.8 \%) \\
3(4.9 \%) \\
12(19.7 \%) \\
8(13.1 \%)\end{array}$ \\
\hline $\begin{array}{l}\text { Are you happy with clinical experience } \\
\text { in addiction Psychiatry? } \\
\text { Yes } \\
\text { No }\end{array}$ & $\begin{array}{l}85.6 \%(53) \\
9(14 \%)\end{array}$ \\
\hline
\end{tabular}

Screening of medical interns on use of substance was assessed by Brief Tobacco, alcohol and drug use screening questionnaire. (Details in table no 3.)
Table 3: Brief Screening for Substance Use

\begin{tabular}{|l|l|l|}
\hline Substance & Current Users & Ever used \\
\hline Tobacco & Yes=7(11.5\%) & Yes=12 (19.7\%) \\
& No=54(88.5\%) & No=49 $(80.3 \%)$ \\
\hline Alcohol & Yes=12 (19.7\%) & Yes=10 (16.4\%) \\
& No=49 (80.3\%) & No=51 $(83.6 \%)$ \\
\hline Cannabis & Yes=2 (3.2\%) & Yes=17 (27.9\%) \\
& No=59 (96.8\%) & No=44 (72.1\%) \\
\hline Other & Yes=0 (0\%) & Yes=1 (1.63\%) \\
Drugs(heroin) & No=61(100\%) & No=60 (98.37\%) \\
\hline
\end{tabular}

When we tried to see the relationship between various components of socio demographic factors( e.g. gender),completion of posting , history of use of substance etc. with total score The Addiction Belief Scale (ABS) using independent sample $\mathrm{T}$ test, no significant findings was seen. Higher score of ABS scale would represent the free will model addiction rather than biological model and not significant finding reflected biological model view of addiction (details in table no 4)

Table 4: Comparision of the mean of the total belief scale with different variables (Independent sample T test applied)

\begin{tabular}{|l|l|l|}
\hline Various component & $\begin{array}{l}\text { ABS total score } \\
(\text { Mean } \pm \text { SD })\end{array}$ & $\begin{array}{l}\text { T-value/ } \\
\text { P value }\end{array}$ \\
\hline Gender & & $0.152 / 0.8$ \\
Male & $48.20(\mathrm{SD}=7.95)$ & \\
Female & $48.50(\mathrm{SD}=7.14)$ & \\
\hline Completion of posting & Total scale & $0.58 / 0.56$ \\
Y & $48.81(\mathrm{SD}=7.49)$ & \\
$\mathrm{N}$ & $47.67(\mathrm{SD}=7.55)$ & \\
\hline Happiness with posting & Total scale & $1.34 / 0.18$ \\
$\mathrm{Y}$ & $47.82(\mathrm{SD}=7.21)$ & \\
$\mathrm{N}$ & $51.44(\mathrm{SD}=8.64)$ & \\
\hline Career options & Total scale & $0.08 / 0.9$ \\
Other medical & $48.07(\mathrm{SD}=7.47)$ & \\
Surgical & $47.89(\mathrm{SD}=7.27)$ & \\
\hline Current tobacco use & Total scale & $0.57 / 0.38$ \\
Y & $50.71(\mathrm{SD}=5.82)$ & \\
$\mathrm{N}$ & $48.05(\mathrm{SD}=7.65)$ & \\
\hline Current alcohol use & Total scale & $0.45 / 0.67$ \\
Y & $49.25(\mathrm{SD}=5.32)$ & \\
$\mathrm{N}$ & $49.48(\mathrm{SD}=7.94)$ & \\
\hline
\end{tabular}




\section{DISCUSSION:}

Majority of the students had finished their 2week psychiatric internship, and even remaining interns were already posted on emergency duties. Emergency department is the first site to assess, manage and transfer patient with alcohol dependence with withdrawal symptoms and other SUD. During their posting in psychiatric ward, they are supposed to do detail workup, interview the patient and their family members and assist in the treatment process. They have to stay as rotational night shift duties and report to the consultant the next day. Many interns are familiar with treatment process especially for alcohol withdrawal phase and have been part of clinical rounds, counseling process and treatment process. So in the absence of psychiatric residents in KISTMCTH, they have the first hand experience of managing patient which is one of the reasons of increase exposure to patient care, and high percentage of happiness in interaction of the patient with SUD. This is not always a common finding. A study found that significant negative attitudes among students were present and increased with each year in medical training 9 . Dislike for specific groups of substance abusers were also observed, with $32 \%$ of the first-year students reporting dislike for alcohol abusers, $29 \%$ indicating dislike for heroin users and 22\% disliking smokers 9 .Tribhuwan University based medical college has strong clinical curriculum with relatively high value of marks in final exams and students have to go through long cases and oral evaluations in final exams unlike medical colleges affiliated to Kathmandu University. At least three out of 10 cases are of substance dependence especially alcohol dependence cases. This could be the reason of high percentage of exposure among current interns during their medical students' days. Another study found that negative attitudes towards patients with SUDs among medical students improved as students progressed through their graduate medical education ${ }^{10}$. This could be another explanation for positive attitude seen in the group of interns dealing with SUD.

Average 3 hours of clinical posting are devoted for detail discussion with students on management of substance use disorder. This is not sufficient for understanding complex issues like addiction related problems. Curriculum coverage in German medical schools of alcohol use disorders and smoking is half that of diabetes and hypertension, and in the final year of their undergraduate training most students reported inadequate knowledge of how to intervene to address those issues. ${ }^{11}$ Other studies also reported similar finding regarding lack and inconsistency of the curriculum ${ }^{12}$

Screening medical students on life time use of alcohol and tobacco was reported on other studies as well. An opportunistic study done in India focusing on 76 medical colleges from India and 4 medical colleges from Nepal reported $25 \%$ and $30 \%$ life time use for alcohol and tobacco respectively and current use for 7 and 6 $\%$ respectively. Cannabis is least commonly used and male gender is associated with greater use of substances among medical students. ${ }^{13}$ Direct study related to interns couldn't be extracted. Regarding breakdown of Addiction belief scale, predominant of model explaining biological model of illness was noted in majority of the interns which is an expected finding. Similar finding has been seen in other studies based on medical students. ${ }^{8}$ However no statistically significant finding was noted in belief model scales especially. when compared and contrasted to difference in gender, completion of posting in psychiatry, age, duration of posting, or self use of different types of substance Similar studies from other universities may unfold different pictures.

There is limited studies assessing it especially from Nepal. As the curriculum and evaluation system is not consistent in different universities, multi-centric studies can give a clear picture.

\section{CONCLUSION:}

Medical interns in this study showed the predominant of a disease model as a belief system for disturbance presented in substance use disorder. A good curriculum, exposure and teaching and learning hours can make lots of difference. Further studies in different colleges can give a clear picture.

\section{ACKNOWLEDGEMENT: None.}

CONFLICT OF INTEREST: None 


\section{REFERENCES:}

1. Vos T, Barber RM, Bell B et al. Global, regional, and national incidence, prevalence, and years lived with disability for 301 acute and chronic diseases and injuries in 188 countries, 1990-2013: a systematic analysis for the Global Burden of Disease Study 2013. Lancet. 2015 Aug 22; $386 \quad$ (9995):743-800. (doi: 10.1016/S01406736(15)60692-4.)

2. Substance Abuse and Mental Health Services Administration (SAMHSA). (2009). Results from the 2008 National Survey on Drug Use and Health: National Findings. Rockville, MD: Office of Applied Studies, NSDUH Series H-36, HHS Publication No. SMA 09-4434 3. Pottick KJ, Kirk SA, Hsieh DK, Tian X. judging mental disorder in youths: Effects of client, clinician, and contextual differences.J Consult Clin Psychol. 2007 Feb;75(1):1-8 (http://dx.doi.org/10.1037/0022006X.75.1.1)

4. Van Boekel LC, Brouwers EP, Van Weeghel J, Garretsen HF. Stigma among health professionals towards patients with substance use disorders and its consequences for healthcare delivery: systematic review. DrugAlcohol Depend. $2013 \quad$ Jul 1;131(1):23-35. ( doi:10.1016/j.drugalcdep.2013.02.018)

5. $\quad$ Pariyar K. Rehabilitation centers remain rampant in lack of effective monitoring. 2016 (Cited on April2019).

(https://myrepublica.nagariknetwork.com/news/rehabilitati on-centers-remain-rampant-in-lack-of-effective-

monitoring/

6. 13 patients escape, 21 rescued from rehab centre. (Cited on april 2019). (https://thehimalayantimes.com/kathmandu/13-patientsescape-21-rescued-from-rehab-centre)

7. Rosta J. Is alcoholism a self-induced disease? A survey among doctors in Aarhus, Denmark and in Mainz, Germany. Nord J Psychiatry. 2004 Jun 1;58(3): 21922(DOI:10.1080/08039480410006269)

8. Schaler JA. The addiction belief scale. Int J Addict. 1995 Jan 1;30(2):117-34(PMID:7759167)

9. Silins E, Silins E, Conigrave KM, Silins E, Conigrave KM, Rakvin C, Silins E et al., The influence of structured education and clinical experience on the attitudes of medical students towards substance misusers. Drug Alcohol Rev. 2007 Jan 1;26(2):191-200.( DOI: 10.1080/09595230601184661)

10. Landy J, Hynes J, Checinski K, Crome IB. Knowledge of and attitudes to substance misuse in undergraduate British medical students. Drugs: education, prevention and policy. 2005 Apr 1;12(2):13748.(https://doi.org/10.1080/0968763042000303261)

11. Strobel L, Schneider N, Krampe H, Beißbarth T, Pukrop T, Anders S, West R, Aveyard P, Raupach T. German medical students lack knowledge of how to treat smoking and problem drinking. Addiction. 2012 May 03;107(10):1878-1882. (doi: $10.1111 / j .1360$ 0443.2012.03907.x.)
12. Ayu A, P, Schellekens A, F, A, Iskandar $S$, Pinxten L, De Jong C, A, J: Effectiveness and Organization of Addiction Medicine Training Across the Globe. Eur Addict Res 2015;21:223-239. (doi: 10.1159/000381671) 13. Rai N,Gaete J,Girotra S, Pal HR, Araya $R$. Substance use among medical students:Time to reignite the debate? Natl Med J India 2008;21:75-8(PMID:18807312) 